\title{
Hyperbilirubinemia in atazanavir-treated human immunodeficiency virus-infected patients: the impact of the UGTIAI*28 allele
}

This article was published in the following Dove Press journal:

Pharmacogenomics and Personalized Medicine

23 August 2017

Number of times this article has been viewed

\author{
Anushka Naidoo' \\ Kogieleum Naidoo ${ }^{1,2}$ \\ Veron Ramsuran ${ }^{3}$ \\ Millidhashni Reddy' \\ Nesri Padayatchi ${ }^{1,2}$
}

'Centre for the AIDS Programme of Research in South Africa, ${ }^{2} \mathrm{MRC}$ CAPRISA HIV-TB Pathogenesis and Treatment Research Unit, Doris Duke Medical Research Institute, ${ }^{3} \mathrm{~S}$ chool of Laboratory Medicine and Medical Sciences, University of KwaZuluNatal, Durban, South Africa
Correspondence: Anushka Naidoo Centre for the AIDS Program of Research in South Africa, Second Floor. K-RITH Tower Building, Nelson R Mandela School of Medicine, University of Kwa-Zulu Natal, Private Bag X7, Congella, 4013 Durban, South Africa Tel +27312601963

Email anushka.naidoo@caprisa.org

\section{Dear editor}

Panagopoulos et al ${ }^{1}$ reviewed the effects of the $U G T 1 A 1 * 28$ polymorphism on Reyataz ${ }^{\mathbb{B}}$ (atazanavir)-related hyperbilirubinemia in human immunodeficiency virus (HIV)-infected patients that may result in increased severity and drug discontinuation in some patients. The effects of the UGT1A1 polymorphisms on the pharmacokinetics of other antiretroviral drugs such as Isentress ${ }^{\circledR}$ (raltegravir) and Edurant ${ }^{\circledR}$ (rilpivirine) are also discussed. We respond here on the relevance of the study findings in the South African context.

The antiretroviral protease inhibitor (PI) atazanavir inhibits hepatic uridine diphosphate-glucuronosyltransferase (UGT) 1A1, thereby preventing the glucuronidation and elimination of bilirubin. ${ }^{2}$ This may result in hyperbilirubinemia in $>50 \%$ of patients, with jaundice that can cause premature discontinuation of atazanavir in $~ 2 \%-8 \%$ of patients. ${ }^{2}$ Risk for bilirubin-related discontinuation of atazanavir is substantially increased among individuals who carry two $\mathrm{TA}_{\mathrm{n}}$ repeat polymorphisms within the UGT1A1 loci: $\mathrm{TA}_{7}(U G T 1 A 1 * 28)$ and $\mathrm{TA}_{8}(U G T 1 A 1 * 37)$ that reduce gene transcription, with reported positive predictive values for discontinuation ranging from $20 \%$ to $60 \%$ depending on race or ethnicity. ${ }^{2}$

Prevalence of the $U G T 1 A^{*} 28$ polymorphism is reported to be between $9 \%$ and $60 \%$ in African populations. ${ }^{1}$ One study examining the South African population $(\mathrm{n}=197)$ reported $U G T 1 A 1 * 28$ and $U G T 1 A 1 * 37$ frequencies as $\sim 34 \%$ and $6 \%$ of the population, respectively. ${ }^{3}$ We recently tested the prevalence of $U G T 1 A 1$ polymorphisms in a cohort of 172 tuberculosis patients (73\% HIV coinfected) in KwaZulu-Natal, South Africa, within the Improving Retreatment Success study (NCT02114684). The prevalence of UGTIA1*28 and UGT1A1*37 was found to be $\sim 23 \%$ and $8 \%$, respectively. This suggests that approximately one-third of South African patients may be at potential risk for atazanavir-related hyperbilirubinemia resulting in drug discontinuation.

South Africa is one of the highest HIV-burden countries in the world and has the largest antiretroviral treatment program globally, with $>3.4$ million people on treatment. ${ }^{4}$ The current first-line drug regimen used in South Africa includes efavirenz, emtricitabine, and tenofovir; however, it is estimated that between $8 \%$ and $23 \%$ of patients will be switched to a second-line regimen within 5 years on treatment. ${ }^{5}$ The South African National treatment guideline includes PIs as the backbone of the second-line drug regimens. Aluvia ${ }^{\circledR}$ (ritonavir-boosted lopinavir) is more commonly prescribed; however, atazanavir is the preferred alternate PI in patients who are unable 
to tolerate lopinavir such as those patients with gastrointestinal side effects, or those with dyslipidemia at high risk of cardiovascular events. Atazanivir is also recommended as a part of postexposure prophylaxis in South Africa.

The increasing rates of acquired and transmitted drug resistance seen in patients in HIV-endemic settings clearly indicate a growing demand for second-line drugs such as atazanavir and newer agents including raltegravir and rilpivirine. Data describing the prevalence and impact of genetic variability on antiretroviral drug-metabolizing enzymes (DMEs) such as UGT1A1 from HIV endemic geographical locations including South Africa are lacking. Investigating the extent to which allelic variation of key DMEs impacts pharmacokinetics, drug exposures, therapeutic efficacy, and risk of serious adverse events is critical to ensure safe and sustainable virologic suppression. Moreover, as genetic testing assays for polymorphisms in genes coding for DMEs become cheaper, easier to access, and interpret, more data from studies are needed to guide clinical decision-making based on pharmacogenetics.

\section{Disclosure}

The authors report no conflicts of interest in this communication.

\section{References}

1. Panagopoulos P, Maltezos M, Hatzakis A, Paraskevis D. Hyperbilirubinemia in atazanavir treated HIV-infected patients: the impact of the UGT1A1*28 allele. Pharmgenomics Pers Med. 2017;10:205-208.

2. Gammal RS, Court MH, Haidar CE, et al. Clinical Pharmacogenetics Implementation Consortium (CPIC) Guideline for UGT1A1 and Atazanavir Prescribing. Clin Pharmacol Ther. 2016;99(4):363-369.

3. Horsfall LJ, Zeitlyn D, Tarekegn A, et al. Prevalence of clinically relevant UGT1A alleles and haplotypes in African populations. Ann Hum Genet. 2011;75(2):236-246.

4. WHO. Global AIDS Update 2016; 2016. Geneva, Switzerland: World Health Organisation. Available from: http://www.who.int/hiv/pub/arv/ global-AIDS-update-2016_en.pdf?ua=1. Accessed August 2, 2017.

5. Onoya D, Nattey C, Budgell E, et al. Predicting the need for third-line antiretroviral therapy by identifying patients at high risk for failing second-line antiretroviral therapy in South Africa. AIDS Patient Care STDS. 2017;31(5):205-212.

Dove Medical Press encourages responsible, free and frank academic debate. The content of the Pharmacogenomics and Personalized Medicine 'letters to the editor' section does not necessarily represent the views of Dove Medical Press, its officers, agents, employees, related entities or the Pharmacogenomics and Personalized Medicine editors. While all reasonable steps have been taken to confirm the content of each letter, Dove Medical Press accepts no liability in respect of the content of any letter, nor is it responsible for the content and accuracy of any letter to the editor.

\section{Publish your work in this journal}

Pharmacogenomics and Personalized Medicine is an international, peerreviewed, open access journal characterizing the influence of genotype on pharmacology leading to the development of personalized treatment programs and individualized drug selection for improved safety, efficacy and sustainability. This journal is indexed on the American Chemical
Society's Chemical Abstracts Service (CAS). The manuscript management system is completely online and includes a very quick and fair peer-review system, which is all easy to use. Visit http://www.dovepress. $\mathrm{com} /$ testimonials.php to read real quotes from published authors. 